\title{
TEM and EELS Study of Dislocation Loops in Reduced $\mathrm{BaTiO}_{3}$
}

\author{
G. Y. Yang, E. C. Dickey, C. A. Randall
}

Center for Dielectric Studies, Materials Research Institute, Department of Materials Science and Engineering, The Pennsylvania State University, University Park, PA 16802

To avoid the oxidation of inner electrodes, $\mathrm{Ni}-\mathrm{BaTiO}_{3}$ multilayer ceramic capacitors (MLCCs) are fired in reducing atmosphere. Consequently, the $\mathrm{BaTiO}_{3}$ becomes oxygen deficient. Structural defects, such as dislocation loops, are often observed in the reduced $\mathrm{BaTiO}_{3}$ perovskite lattice. A few TEM studies have shown that the dislocation loops (DL) mostly lie on $\{100\}$ planes with Burgers vectors of type $<100>{ }^{1-2}$ In this work, transmission electron microscopy (TEM) coupled with electron energy-loss spectroscopy (EELS) have been used to study chemical characteristics of the dislocation loops.

The Ni-BaTiO $\mathrm{MLCCs}_{3}$ were fabricated by co-firing $\mathrm{Ni}$ internal electrodes with $\mathrm{BaTiO}_{3}$ dielectric layers at $\sim 1300{ }^{\circ} \mathrm{C}$ in a $\mathrm{PO}_{2}$ of $\sim 10^{-12} \mathrm{~atm}$. TEM observations of thinned specimens were performed using a JEOL 2010F transmission electron microscope equipped with a field-emission gun operated at $200 \mathrm{kV}$. Electron energy-loss spectra (EELS) were acquired with a Gatan Enfina parallel electron energy-loss spectrometer attached to the JEOL 2010F microscope. EEL spectra were recorded in TEM-diffraction mode with a collection angle of $14 \mathrm{mrad}$, and analyzed with Gatan Digital Micrograph software.

Figure 1 (a) shows a typical bright-field TEM image obtained from co-fired $\mathrm{BaTiO}_{3}$ grains. A high density of dislocation loops is observed in $\mathrm{BaTiO}_{3}$. Since image contrast of the dislocation loops is highly sensitive to crystal orientation, the dislocation loops are observed in some grains although the dislocation loops are equally present in other grains. Figure 1(b) shows the EEL spectra obtained from the dislocation loop and just away from the defects, as noted by the circles in figure 1 (b). The fine structures of the $\mathrm{Ti} \mathrm{L}_{2,3}$ and $\mathrm{O} \mathrm{K}$ edges are shown in figure 1 (b). In the EEL spectrum obtained from the regions away from the dislocation loops, a clear split in the $\mathrm{Ti} \mathrm{L}_{2,3}$ edges $\left(\mathrm{t}_{2 \mathrm{~g}}\right.$ and $\left.\mathrm{e}_{\mathrm{g}}\right)$, indicative of $\mathrm{Ti}^{4+}$, is observed. The fine structures of $\mathrm{O} \mathrm{K}$ edges are noted by capital letters $\mathrm{A}, \mathrm{B}, \mathrm{C}$, and $\mathrm{D}$. In the spectrum taken from the dislocation loop, characteristics of the fine structures of the Ti $\mathrm{L}_{2,3}$ and $\mathrm{O} \mathrm{K}$ edges become faint. Such evolutions in $\mathrm{Ti}_{2,3}$ and $\mathrm{O} \mathrm{K}$ edges is associated with local oxygen deficiency. ${ }^{3-5}$

Shown in figure 2 is the EEL spectrum obtained with energy dispersion of $0.5 \mathrm{eV} / \mathrm{channel}$. Atomic ratio of $\mathrm{Ti}$ and $\mathrm{Ba}$ were calculated through quantification of the EEL spectra obtained from the dislocation loops and away from the dislocation loops with the integration window with of $50 \mathrm{eV}$. The k-factor measured from a standard $\mathrm{BaTiO}_{3}$ sample was used. More than 20 pairs of EEL spectra were analyzed and the ratios, $\mathrm{C}_{\mathrm{Ti}} / \mathrm{C}_{\mathrm{Ba}}$, can be classified as into 3 groups: $\left(\mathrm{C}_{\mathrm{Ti}} / \mathrm{C}_{\mathrm{Ba}}\right)_{\mathrm{DL}}<\left(\mathrm{C}_{\mathrm{Ti}} / \mathrm{C}_{\mathrm{Ba}}\right)_{\text {away }}$ DL, $\left(\mathrm{C}_{\mathrm{Ti}} / \mathrm{C}_{\mathrm{Ba}}\right)_{\mathrm{DL}} \approx\left(\mathrm{C}_{\mathrm{Ti}} / \mathrm{C}_{\mathrm{Ba}}\right)_{\text {away DL}}$, and $\left(\mathrm{C}_{\mathrm{Ti}} / \mathrm{C}_{\mathrm{Ba}}\right)_{\mathrm{DL}}>\left(\mathrm{C}_{\mathrm{Ti}} / \mathrm{C}_{\mathrm{Ba}}\right)_{\text {away DL }}$, implying that the dislocation loops in reduced $\mathrm{BaTiO}_{3}$ may be generated through three possible Schottky reactions: complete

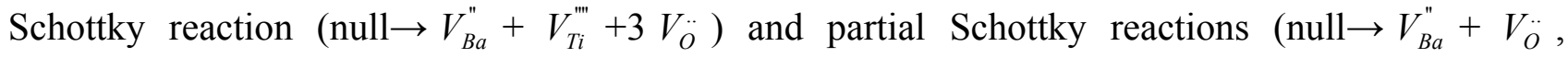
null $\left.\rightarrow V_{T i}^{\prime \prime \prime \prime}+2 V_{O}^{*}\right){ }^{6}$ It is suggested that the formation of dislocation loops in reduced $\mathrm{BaTiO}_{3}$ should be associated with local clustering of oxygen vacancies and/or metallic vacancies. 

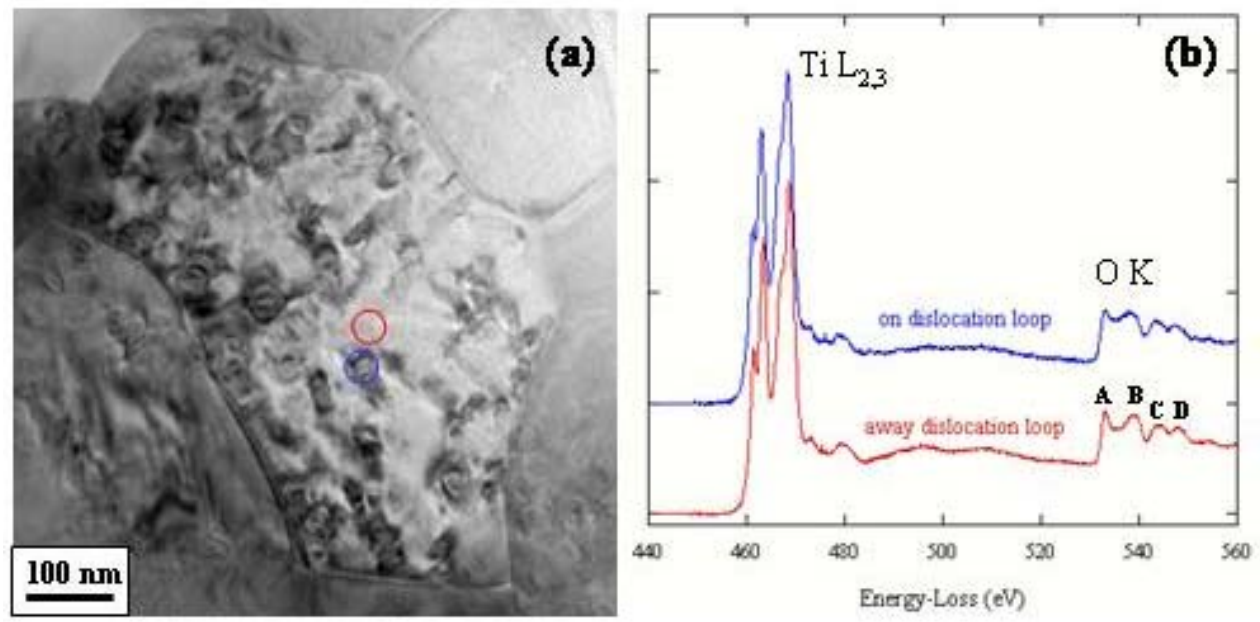

Figure 1. (a) BF TEM image of dislocation loops in reduced $\mathrm{BaTiO}_{3}$ grains, (b) EEL spectra obtained from dislocation loops and just away from the dislocation loops.

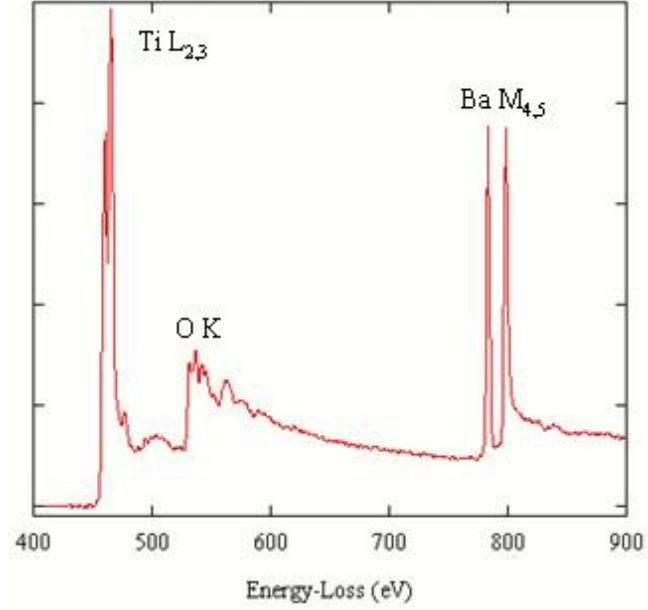

Figure 2. EEL spectrum obtained with energy dispersion of $0.5 \mathrm{eV} /$ channel showing the $\mathrm{Ti} \mathrm{L}_{2,3}, \mathrm{O} \mathrm{K}$ and $\mathrm{Ba} \mathrm{M}_{4,5}$ edges. The integration window width of $50 \mathrm{eV}$ was used to quantify $\mathrm{Ti}$ and $\mathrm{Ba}$ atomic ratio.

\section{References:}

1. C. Metzmacher and K. Albertsen, J. Am. Ceram. Soc., 2001; 84: 821.

2. T. Suzuki, M. Ueno, Y. Nishi, and M. Fujimoto, J. Am. Ceram. Soc., 2001; 84: 200.

3. G. Y. Yang, E. C. Dickey, C. A. Randall, D. E. Barber, P. Pinceloup, M. A. Henderson, R. A. Hill, J. J. Beeson, and D. J. Skamser, J Appl Phys, 2004; 96:7492.

4. G. Y. Yang, E. C. Dickey, C. A. Randall, D. E. Barber, P. Pinceloup, M. A. Henderson, R. A. Hill, J. J. Beeson, and D. J. Skamser, J Appl Phys, 2004; 96: 7500.

5. G. Y. Yang, E. C. Dickey, C. A. Randall, M. S. Randall, and L. A. Mann, J Appl Phys, 2003; 94:5990.

6. Y.M. Chiang and T. Takagi, J. Am. Ceram. Soc., 1990; 73: 3278.

Acknowledgement:

This work was supported by the National Science Foundation, as part of the Center for Dielectric Studies under Grant No. 0120812. The authors wish to acknowledge the Materials Research Institute TEM Facility at The Pennsylvania State University. 